\title{
Short-term Outcomes of Modified Y-Graft Technique in Acute Type A Aortic Dissection Using the Femoral Artery Bypass and One Minute Systemic Circulatory Arrest Technique
}

\author{
Xiangfei Sun \\ Shandong Provincial Hospital Affiliated to Shandong First Medical University \\ Qi Zhao \\ Shandong Provincial Hospital Affiliated to Shandong First Medical University \\ Yufeng Huo \\ Qilu Hospital of Shandong University \\ Jinfeng Zhou \\ Qilu Hospital of Shandong Universtiy
}

Fen Zhao

Qilu Hospital of Shandong University

Yimin Liu

Qilu Hospital of Shandong University

Yonghai Du

Qilu Hospital of Shandong University

Songxiong $\mathrm{He}$

Qilu Hospital of Shandong University

Chao Liu

Qilu Hospital of Shandong University

Detian Jiang

Qilu Hospital of Shandong University

Wenyu Sun ( $\sim$ sdusunwenyu@sina.com )

Department of cardiovascular surgery, Qilu Hospital of Shandong University

\section{Research article}

Keywords: modified Y-graft technique, femoral artery bypass, one minute systemic circulatory arrest, acute type A aortic dissection

Posted Date: February 28th, 2020 
DOI: https://doi.org/10.21203/rs.2.24839/v1

License: (c) (1) This work is licensed under a Creative Commons Attribution 4.0 International License. Read Full License

Version of Record: A version of this preprint was published at Journal of Cardiothoracic Surgery on May 20th, 2020. See the published version at https://doi.org/10.1186/s13019-020-01156-5. 


\section{Abstract}

Objective: Aortic arch replacement in acute type A aortic dissection patients remains a most challenging cardiovascular operation. This article aims to show our Modified Y-Graft Technique using the Femoral Artery Bypass (FAB) and the One Minute Systemic Circulatory Arrest (OSCA) Technique and assess the short-term outcomes of the patients.

Methods: Between February 2015 and November 2017, 51 patients with acute type A aortic dissection underwent aortic arch replacement. Among them, 23 patients' procedure used FAB and 28 patients utilized both FAB and OSCA. The intraoperative data and postoperative follow-up data were recorded. The follow-up data of patients with traditional Y-graft technique were collected from previous reported studies.

Results: In FAB group, two patients died for pulmonary infection (30-day survival rate $91.3 \%$ ), and two patients paralyzed from the waist down. The hemodialysis was performed for five patients $(21.7 \%)$ before hospital discharge. Fifteen patients (65.2\%) received more than 2-day's respiratory support and 8 patients (34.8\%) received more than 5-day's respiratory support. These follow-up data are basically flat or precede to the patients with traditional Y-graft technique. Furthermore, compared to the FAB Group, the morbidity of the neurologic dysfunction and the acute renal failure was significantly reduced in FAB+OSCA Group. Besides, the respiratory support, the length of the postoperative stay and the ICU stay were shortened.

Conclusions: This study clarified the feasibility of FAB and OSCA technique in modifying Y-graft technique. The acute type $A$ aortic dissection patients tend to have less surgical complications and favorable short-term outcomes by this surgery.

\section{Introduction}

The first successful aortic arch replacement was reported before more than fifty years. With the development of the surgical technique and the improvement of patient care, the aortic arch can be repaired more safely. However, the total aortic arch replacement in acute type A aortic dissection patients remains a most challenging cardiovascular operation, which incurs high risk of cerebral damage and acute renal failure, and consequently, a considerable risk of operative mortality. In recent years, it is reported that the 30 -day mortality as high as $18 \%$ and stroke rates as high as $10 \%$ [1].

In 2002, Spielvogel and colleagues developed the Y-Graft technique to enable antegrade selective cerebral perfusion [2]. The individual reconstruction of brachiocephalic branches using a trifurcated graft contributed to the prognosis of the patients $[3,4]$. However, the outcome of the aortic arch replacement surgery may largely affected by not only the surgeon's skill but also on the tentative surgery techniques [5, 6]. In recent years, it is reported that in patients receiving aortic arch replacement, the 30-day mortality is as high as $18 \%$ and stroke rates is as high as $10 \%$ [7-9]. The exploration of feasible and beneficial modification on this technique is still urgent. 
Basing on the traditional Y-Graft technique, our team firstly modified it using Femoral Artery Bypass (FAB) and One Minute Systemic Circulatory Arrest (OSCA) Technique to simplify arch reconstruction, reduce embolization and avoid the cerebral ischemia.

In recent two years, we encountered 51 cases of acute type A aortic dissection receiving aortic arch replacement with our modified Y-Graft Technique. The perioperative data and short-term follow-up data such as perfusion time, 30-days survival rate, neurologic dysfunction, length of respiratory support, acute renal failure were recorded for all patients. The follow-up data of patients with traditional Y-graft technique were collected from previous reported studies. This article aims to show our Modified Y-Graft Technique and to assess the short-term outcomes of the patients.

\section{Patients And Methods}

\section{Patients}

We conduct a retrospective review on data from 51 patients who underwent aortic replacement between February 2015 and November 2017 in our hospital. The clinical features of the patients are showed in Table 1. Of these patients, 23 patients (45.1\%) underwent modified Y-Graft technique using the FAB technique, and 28 (54.9\%) underwent total arch replacement by the modified Y-Graft technique with the FAB+OSCA techniques. The perioperative data and short-time follow-up data were recorded for all patients. For the use of materials for research purposes, written informed consent was obtained from each patient. This study was approved by the Ethics Committee of Qilu Hospital of Shandong University.

\section{Surgical Technique}

The surgical procedure can be divided into three stages.

\section{Stage 1: The reconstruction of three branches ( using FAB technique, Figure 1).}

The femoral artery was exposed through a small incision inferior inguinal ligament; The left axillary artery was exposed through a small infra-clavicular incision; A median sternotomy was performed with extension of the incision superiorly along the medial border of the left sternocleidomastoid muscle. The brachiocephalic vessels were exposed.

Intro-venous heparin was administered to achieve an activated clotting time (ACT) above 350 seconds. A $10 \mathrm{~mm}$ graft ( $4 \mathrm{~cm}$ length) was end-to-side anastomosed to the femoral artery and then one of the $10 \mathrm{~mm}$ extracorporeal circulation's arterial tubes was tightly connected to this graft. Another $10 \mathrm{~mm}(15 \mathrm{~cm}$ length) graft was end-to-side anastomosed to the left subclavian artery with a 5-0 polypropylene suture. The other end of this graft was tunneled via the second intercostal space into the mediastinum on demand. The left common carotid artery was cannulated with an arterial catheter. The femoral artery-toleft common carotid artery bypass was finished. The left common carotid artery was transected just distal to its origin at the aortic arch. Another $8 \mathrm{~mm}$ graft was anastomosed to the left common carotid artery with a 5-0 polypropylene suture. The first $10 \mathrm{~mm}$ graft (connected with the left subclavian artery) 
measured to the appropriate length and was side-to-side anastomosed to the second $8 \mathrm{~mm}$ graft (connected with the left common carotid artery) with 5-0 polypropylene suture. The free-end of the first $10 \mathrm{~mm}$ graft was tightly connected to an extracorporeal circulation's arterial tubes. The free-end of the second $8 \mathrm{~mm}$ graft (connected with the left common carotid artery) was clamped. Remove the left common carotid artery' catheter. So far both femoral artery-to-left common carotid artery bypass and the femoral artery-to-left subclavian artery bypass had been finished. As for the innominate artery, the procedure of the cannulation and anastomosis was similar to the left common carotid artery's. The innominate artery was cannulated with an arterial catheter. A femoral artery-to- innominate artery bypass was finished. Then the innominate artery was transected. A $12 \mathrm{~mm}$ graft was end-to-end anastomosed to the innominate artery with a 5-0 polypropylene suture. The free-end of the $12 \mathrm{~mm}$ graft was clamped.

Ultimately, without the assistance of cardiopulmonary bypass unit, femoral artery-to-left common carotid artery bypass, femoral artery-to-left subclavian artery bypass and femoral artery-to- innominate artery bypass were completed in a room temperature with the continuous selective bilateral cerebral perfusion. Every graft above was carefully deaired and restoring perfusion to the head and upper extremities (Fig 1).

\section{Stage 2: The reconstruction of the proximal aortic root.}

Open the pericardium, after cannulation of the superior and inferior vena cava, the extracorporeal circulation and cooling were started. Cross-clamped the ascending aortic $\left(32^{\circ} \mathrm{C}\right)$ and the cardioplegic solution was usually perfused through a coronary sinus cannulation to make the heart arrested. After the cardioplegic cardiac arrest, the aortic valve repair or replacement (Bentall) was performed if we found the significant aortic valve insufficiency through TEE. The ascending aortic was also replaced by the graft which was anastomosed to the aortic sinotubular junction or the artificial valve ring.

\section{Stage 3: The reconstruction of the aortic arch (using OSCA technique, Figure 2).}

The completion of the reconstruction of the proximal aortic root usually coincided with the end of core cooling (target temperature: $32^{\circ} \mathrm{C}$ ). At the beginning of this stage, the patient was placed in slight Trendelenburg position, the head was packed in ice. Moved the cross-clamp to the distal aortic arch (between the innominate artery and the left common carotid artery) and trimmed the aortic arch.

Hypothermic circulatory arrest was started when we removed the clamp. The intraoperative stent (Stented Graft System In Surgical Operation) was placed into the distal aortic arch and then cross-clamped the aortic arch immediately after de-airing (Fig 2A). Thereafter the lower-body perfusion restored and active rewarming was begun. The duration of the hypothermic circulatory arrest was more or less than one minute. The following operation we could perform in an unhurried fashion. The proximal of the self-aortic arch and the intraoperative stent's graft was trimmed and the sandwich treatment was performed (Fig 2B). The previously placed graft on the root was retracted, stretched and measured to the site of distal anastomosis. Graft-to-graft anastomoses were performed with 2-0 polypropylene sutures. Then the aortic cross-clamp was removed. 
Before the cannulation of the innominate artery and the graft which was connected to left subclavian artery removed, the $8 \mathrm{~mm}$ graft was end-to-side anastomosed to the $12 \mathrm{~mm}$ graft (innominate artery). The free-end of the $12 \mathrm{~mm}$ graft was end-to-side anastomosed to the ascending graft in ideal site (Fig $2 \mathrm{C}$ ). Antegrade bilateral cerebral and upper extremity perfusion was not interrupted. On completion of this final anastomosis, active rewarming continued until the patient can be weaned from cardiopulmonary bypass.

\section{Variables and statistical analysis}

Patients were followed by cardiologists. Telephone interview of patients was performed. The follow-up period was 30 days after operation. We defined operative mortality as death within 30 days of operation. The neurologic dysfunction was defined as any new clinically or radiographically evident brain injury present after operation. Especially the temporary or permanent paresis or paralysis that resolved before hospital discharge. Acute renal failure was defined as the need to initiate the renal support with hemofiltration. Statistical analysis was performed using statistical software of SPSS 16.0 for Windows 7. When the quantitative variables obeyed normal distributed, it was presented as mean $\pm S D$. If the quantitative variables skewed, it was presented as median and interquartile range. We examined all the continuous variables, the $t$ test was used for those continuous variables obeyed normality distribution and the rank-sum test was used for those with skewed distributions. Univariate analysis of operative mortality, acute renal failure, neurologic dysfunction and respiratory support was performed by the X2 test.

\section{Results}

\section{The modified Y-Graft technique using FAB has advantages in shortening the systemic circulatory arrest time and aortic clamp time, and its short-term outcomes is basically flat or precede to Traditional Y-Graft technique.}

Twenty-three acute type A aortic dissection patients underwent modified Y-Graft technique using the FAB technique. The operative data and postoperative data indicating short-term outcomes, including the Cardiopulmonary Bypass time, Systemic circulatory arrest time, Aortic clamp time, Cerebral circulatory arrest time and so on are collected and showed in Table 2.

In the 23 patients using FAB techniques, there were two 30-day deaths (8.7\%), both of them died for pulmonary infection. Two patients paralyzed from the waist down, one of them was transient, and the other one was not restored in our follow-up period. The hemodialysis was performed for five patients $(21.7 \%)$ in our follow- up period. There were 15 patients $(65.2 \%)$ received more than 2-day's respiratory support and 8 patients (34.8\%) received more than 5-day's respiratory support. As for the traditional YGraft technique, we reviewed the previous articles and obtained the corresponding data (shown in Table 2). The result showed that, the follow-up data in the patients using FAB modified Y-Graft technique are basically flat or precede to the data in patients with traditional Y-graft technique. The systemic circulatory arrest time and aortic clamp time were significantly shortened in FAB modified group. 
When using FAB in this surgery, the right brachiocephalic and left common carotid arteries can be reconstructed without cardiopulmonary bypass and cross clamping the aorta, so the systemic circulatory arrest time and aortic clamp time is largely shortened. Besides, all these procedures were performed on a room temperature. Compared with the traditional Y-Graft technique, we can safely reconstruct the supraaortic branches in an unhurried fashion, especially when the surgeon was inexperienced. It was easy to repair a leak immediately after anastomoses of the supra-aortic arteries because of great mobility and little wall tension of the anastomoses.

\section{The Perioperative variables and short-term outcomes are aspiring in Modified Y-Graft technique using $F A B$ and OSCA.}

Perioperative demographics of the patients are shown in Table 3. Our cases were characterized by age (46.1 \pm 8.3$)$, male sex $(78.6 \%)$, Weight $(80.8 \pm 12.6)$, Marfan syndrome (7.1\%), aortic valve regurgitation (28.6\%), smoking, past or current $(75.0 \%)$, hypertension (92.9\%), renal dysfunction (7.1\%), pulmonary disease.

The operative variables are also shown in Table 3, including the median of the cardiopulmonary bypass time $(204 \mathrm{~min})$, the mean systemic circulatory time $(1.6 \mathrm{~min})$, the aortic clamp time $(92.9 \mathrm{~min})$, the cerebral circulatory time $(0 \mathrm{~min})$, the lowest nasopharyngeal temperature $\left(32^{\circ} \mathrm{C}\right)$. Concomitant procedures included aortic valve replacement (10.7\%) and coronary artery bypass grafting (3.6\%).

The operative mortality was $7.1 \%$, with $3.6 \%$ neurologic dysfunction. Among 28 patients, there were 10 patients $(35.7 \%)$ had the prolonged ( $\mathbb{2}$ days) intubation and 3 patients $(10.7 \%)$ had the prolonged $(\mathbb{Z}$ 5 days) intubation. Only one patient (3.6\%) had postoperative renal dysfunction, this patient required temporary hemodialysis before discharge.

\section{The comparison between the Modified Y-Graft technique using FAB and Modified Y-Graft technique using $F A B$ and OSCA}

The comparison of these two groups was shown in Table 3. Preoperative patient characteristics had no significant differences. Compared with the 23 patients who underwent modified Y-Graft technique using FAB procedures, the 28 patients who underwent modified Y-Graft technique using FAB+OSCA had shorter cardiopulmonary bypass time (Fig $3 \mathrm{~A}$ ), systemic circulatory arrest time (Fig 3B), aortic clamp time (Fig $3 \mathrm{C})$ and higher lowest nasopharyngeal temperature $\left(32^{\circ} \mathrm{C}\right)$. The percentage of the concomitant aortic valve replacement was also lower in the patients using FAB+OSCA techniques (Fig 3D). All of these differences were statistically significant (P凶0.05) except for the aortic clamp time. As for the short-term outcomes, the 28 patients who underwent modified Y-Graft technique using FAB+OSCA had an operative mortality of $7.1 \%$ and the morbidity of neurologic dysfunction is $3.6 \%(\mathrm{Fig} 4 \mathrm{~B})$, and these data is statistically equal to the patients only using FAB. Furthermore, the FAB+OSCA patients had significantly shorter respiratory support duration(Fig 4A) and lower morbidity of acute renal failure(Pख0.05, Fig 4B).

\section{Discussion}


Aortic arch replacement remains among the most technically challenging cardiovascular operations, incurring considerable risk for perioperative death, stroke, acute renal failure and so on. With the development of the aortic arch replacement surgery, Sun's procedure is very popular in China in these years. However, we reviewed numbers of articles on Y-Graft technique and learnt the operation in Hartford Cardiovascular Center for one year. The Y-Graft technique, in which a double Y-graft is used to connect brachiocephalic branches to the main aortic graft, was developed to accomplish arch reconstruction, reduce embolization, and minimize related cerebral ischemia. Recently, we encountered 51 cases of acute type A aortic dissection requiring aortic arch replacement. We modified the procedure of the Y-Graft technique and reduced the systemic circulatory arrest time to a minute or so.

Originally, we modified the Y-Graft technique using the femoral artery bypass. By this technique, we can reconstruct the brachiocephalic branches in a room temperature without using the cardiopulmonary bypass. We didn't even open the pericardium. As for the left subclavian artery, it is hard to expose and anastomose. Nerve injury, especially the recurrent laryngeal nerve, is easy to appear. It's not difficult to see that the brachiocephalic branches' reconstruction is easier to perform by our improvement. Besides, it is important but easy to repair a leak immediately after anastomoses of the supra-aortic arteries because of great mobility and little wall tension of the anastomoses. Twenty-three patients underwent this modified technique. Subsequently, we modified the Y-Graft technique using the Femoral Artery Bypass and One Minute Systemic Circulatory Arrest Technique. The latter technique hugely shortens the systemic circulatory arrest time, thus reducing the ischemic time of spinal cord and kidneys. Moreover, the lowest nasopharyngeal/rectal temperature can be kept at $32^{\circ} \mathrm{C}$. To summarize, our modified technique almost eliminate the systemic circulatory arrest time and reduced the cardiopulmonary bypass time and other operative variables.

Although when comparing the traditional Y-Graft technique with the modified Y-Graft technique using FAB (Table 2), some of the indicators are not significantly advanced, but obviously our FAB technique make the operation easier than before. We can accomplish the reconstruction of the supra-aortic arteries in an unhurried fashion and improve the quality of anastomosis. It also provide a good surgical visual field in making distal aortic anastomosis and make the blood leak sealing more easily.

According to the comparison of FAB technique and FAB-OSCA technique (Table 3 ), the FAB-OSCA technique group had shorter cardiopulmonary bypass time and systemic circulatory time and higher lowest nasopharyngeal temperature $\left(32^{\circ} \mathrm{C}\right)$. All of these differences had the statistical significance. It was undoubtedly that all of the outcomes would show us the encouraging result. Nevertheless, both operative mortality and morbidity of neurologic dysfunction had no statistical differences respectively. These negative results may be caused by the small sample size. We hope our future research with larger sample size will show the concrete advantage of FAB-OSCA technique, indicating it as a valuable alternative surgery technique for acute type A aortic dissection patients. 


\section{Conclusion}

This study clarified the feasibility of FAB and OSCA technique in modifying Y-graft technique. The acute type $A$ aortic dissection patients tend to have less surgical complications and favorable short-term outcomes by this surgery. Although when comparing the traditional Y-Graft technique with the modified Y-Graft technique using FAB (Table 2), some of the indicators are not significantly advanced, but obviously our FAB technique makes the operation easier than before. We can accomplish the reconstruction of the supra-aortic arteries in an unhurried fashion and improve the quality of anastomosis. It also provides a good surgical visual field in making distal aortic anastomosis and make the blood leak sealing more easily.

\section{Abbreviations}

FAB, Femoral Artery Bypass; OSCA, One Minute Systemic Circulatory Arrest $₫$ ACT, Activated Clotting Time

\section{Declarations}

\section{Ethical Approval and Consent to participate}

All procedures performed in studies involving human participants were approved by the Ethics Committee of Qilu Hospital of Shandong University. Informed consent was obtained from all individual participants included in the study.

\section{Consent for publication}

All authors have contributed significantly to the content of the article and all authors have read and approve the submission of the manuscript to this journal.

\section{Availability of supporting data}

All data are fully available without restriction.

\section{Competing interests}

The authors have declared that no competing interests exists.

\section{Funding}

The study has no funding.

\section{Acknowledgements}

Not applicable. 
Sun Xiangfei and Sun Wenyu conceived and designed the study. Sun Wenyu, Sun Xiangfei, Huo Yufeng, Liu Yimin, Zhao Fen, Du Yonghai, He Songxiong, Liu Chao, Jiang Detian, and Zhou Jinfeng performed the operations. Zhao Qi performed the statistical analysis. Sun Xiangfei wrote the paper. Sun Wenyu reviewed and edited the manuscript. All authors read and approved the manuscript.

\section{References}

[1] LeMaire SA, Price MD, Parenti JL, Johnson ML, Lay AD, Preventza 0 et al. Early outcomes after aortic arch replacement by using the Y-graft technique. Ann Thorac Surg 2011;91:700-7.

[2] Spielvogel D, Strauch JT, Minanov OP, Lansman SL, Griepp RB. Aortic arch replacement using a trifurcated graft and selective cerebral antegrade perfusion. Ann Thorac Surg 2002;74:S1810-4.

[3] Spielvogel D, Mathur MN, Lansman SL, Griepp RB. Aortic arch reconstruction using a trifurcated graft. Ann Thorac Surg 2003;75:1034-6.

[4] Strauch JT, Spielvogel D, Lauten A, Galla JD, Lansman SL, McMurtry K et al. Technical advances in total aortic arch replacement. Ann Thorac Surg 2004;77:581-89.

[5] Kazui T, Washiyama N, Muhammad BA, Terada H, Yamashita K, Takinami M et al. Total arch replacement using aortic arch branched grafts with the aid of antegrade selective cerebral perfusion. Ann Thorac Surg 2000;70:3-8.

[6] Kazui T, Yamashita K, Washiyama N, Terada H, Bashar AH, Suzuki T et al. Usefulness of antegrade selective cerebral perfusion during aortic arch operations. Ann Thorac Surg 2002;74:S1806-9.

[7] Hagl C, Ergin MA, Galla JD, Lansman SL, McCullough JN, Spielvogel D et al. Neurologic outcome after ascending aorta-aortic arch operations: effect of brain protection technique in high-risk patients. J Thorac Cardiovasc Surg 2001;121:1107-21.

[8] Sasaki H, Ogino H, Matsuda H, Minatoya K, Ando M, Kitamura S. Integrated total arch replacement using selective cerebral perfusion: a 6-year experience. Ann Thorac Surg 2007;83:S805-10.

[9] Kazui T, Yamashita K, Washiyama N, Terada H, Bashar AH, Suzuki K et al. Aortic arch replacement using selective cerebral perfusion. Ann Thorac Surg 2007;83:S796-8.

[10] Spielvogel D, Halstead JC, Meier M, Kadir I, Lansman SL, Shahani R et al. Aortic arch replacement using a trifurcated graft: simple, versatile, and safe. Ann Thorac Surg 2005;80:90-5.

[11] Spielvogel D, Etz CD, Silovitz D, Lansman SL, Griepp RB. Aortic arch replacement with a trifurcated graft. Ann Thorac Surg 2007;83:S791-5.

[12] Minakawa M, Fukuda I, Yamauchi S, Watanabe K, Kawamura T, Taniguchi S et al. Early and longterm outcome of total arch replacement using selective cerebral perfusion. Ann Thorac Surg 2010;90:72- 
[13] Ueda T, Shimizu H, Hashizume K, Koizumi K, Mori M, Shin H et al. Mortality and morbidity after total arch replacement using a branched arch graft with selective antegrade cerebral perfusion. Ann Thorac Surg 2003;76:1951-6.

[14] Kazui T, Bashar AH. Aortic arch replacement using a trifurcated graft. Ann Thorac Surg 2006;81:1552.

[15] Bischoff MS, Brenner RM, Scheumann J, Bodian CA, Griepp RB, Lansman SL et al. Long-term outcome after aortic arch replacement with a trifurcated graft. J Thorac Cardiovasc Surg 2010;140:S71-6.

[16] Ouzounian M, LeMaire SA, Coselli JS. Open aortic arch repair: state-of-the-art and future perspectives. Semin Thorac Cardiovasc Surg 2013;25:107-15.

[17] Shelstad RC, Reeves JG, Yamanaka K, Reece TB. Total Aortic Arch Replacement: Advantages of Varied Techniques. Semin Cardiothorac Vasc Anesth 2016;20:307-13.

\section{Tables}

Table 1. Patient characteristics.

\begin{tabular}{|l|c|}
\hline \multicolumn{1}{|c|}{ Characteristic } & Value \\
\hline Number of patients & 51 \\
\hline Age, years & $46.3 \pm 9.9$ \\
\hline Sex, men : women & $42: 9$ \\
\hline Emergency operation & $49(96.1 \%)$ \\
\hline Marfan syndrome & $4(7.8 \%)$ \\
\hline Aortic valve regurgitation & $18(35.3 \%)$ \\
\hline Diabetes mellitus & $1(2.0 \%)$ \\
\hline Smoking, past or current & $41(80.4 \%)$ \\
\hline Hypertension & $48(94.1 \%)$ \\
\hline Renal dysfunction & $3(5.9 \%)$ \\
\hline Pulmonary disease & $1(2.0 \%)$ \\
\hline Ischemic coronary heart disease & 4 \\
\hline
\end{tabular}

Data are reported as mean $\pm \mathrm{SD}$, median (interquartile range), or number $(\%)$.

Table 2. Traditional Y-Graft techniques vs Modified Y-Graft techniques utilizing Femoral artery bypass (FAB) 


\begin{tabular}{|c|c|c|}
\hline Variates & $\begin{array}{l}\text { Traditional Y-Graft } \\
\text { techniques }\end{array}$ & $\begin{array}{l}\text { Modified Y-Graft techniques utilizing Femoral artery } \\
\text { bypass }(\mathrm{n}=23)\end{array}$ \\
\hline \multicolumn{3}{|l|}{ Operative variables } \\
\hline \multicolumn{3}{|l|}{ Perfusion and ischemic times, minutes } \\
\hline Cardiopulmonary bypass & $\begin{array}{c}141(118-183)^{1} \\
236.2 \pm 52.5^{10} \\
239 \pm 53.1^{11} \\
279 \pm 82^{12} \\
273 \pm 79^{13}\end{array}$ & $236(200-290)$ \\
\hline Systemic circulatory arrest & $\begin{array}{c}65(51-84)^{1} \\
31.2 \pm 6.6^{10} \\
78 \pm 34^{12} \\
69 \pm 22^{13}\end{array}$ & $20.6 \pm 6.9$ \\
\hline Aortic clamp & $\begin{array}{c}53.9 \pm 41.1^{1} \\
144 \pm 55^{12} \\
163 \pm 54^{13}\end{array}$ & $105 \pm 25.7$ \\
\hline Cerebral circulatory arrest & 0 & 0 \\
\hline $\begin{array}{l}\text { Lowest nasopharyngeal/rectal } \\
\text { temperature, }{ }^{\circ} \mathrm{C}\end{array}$ & $\begin{array}{c}22.0^{\circ} \mathrm{C}(19.1-23.7)^{1} \\
12.8 \pm 2.2^{\circ} \mathrm{C}(9.9-19.8) \\
15.8 \pm 2.1^{\circ} \mathrm{C}(12.0-22.1)^{11} \\
24.0 \pm 2.2^{\circ} \mathrm{C}^{12} \\
16-20^{\circ} \mathrm{C}^{14} \\
23^{\circ} \mathrm{C}^{13}\end{array}$ & $28^{\circ} \mathrm{C}$ \\
\hline Concomitant a ortic valve replacement & $\begin{array}{c}40 \%^{1} \\
2.8 \%^{10}\end{array}$ & $(\mathrm{n}=8) 34.8 \%$ \\
\hline Concomitant coronary artery bypass & $\begin{array}{c}9 \%^{1} \\
2.8 \%\end{array}$ & $(n=3) 13.0 \%$ \\
\hline \multicolumn{3}{|l|}{ Outcomes } \\
\hline Operative mortality & $\begin{array}{c}2 \%^{1} \\
4.6 \%^{10} \\
4.7 \%^{11} \\
4.9 \%^{12} \\
6.8 \%^{15} \\
2 \%^{16} \\
6.8 \%^{14} \\
6.8 \%^{13}\end{array}$ & $(n=2) 8.7 \%$ \\
\hline Neurologic dysfunction & $\begin{array}{c}5 \% 1 \\
9.4 \%^{11} \\
9.8 \%^{12} \\
14 \%^{17} \\
5 \%^{16} \\
9.1 \%^{14}\end{array}$ & $(n=3) 13.0 \%$ \\
\hline Respiratory support & $\begin{array}{l}\text { } 20 \%-51 \% 13 \text { days } \\
\square 5 \text { days } \quad 5 \%-30 \% 13\end{array}$ & $\begin{array}{l}\square 2 \text { days }(n=15) 65.2 \% \\
\square 5 \text { days }(n=8) 34.8 \%\end{array}$ \\
\hline Acute renal failure & $\begin{array}{c}11 \%^{1} \\
3.7 \%^{10} \\
6 \%^{11} \\
13.1 \%^{12} \\
5.4 \%^{14} \\
\end{array}$ & $(n=5) 21.7 \%$ \\
\hline
\end{tabular}

Data are reported as mean $\pm \mathrm{SD}$, median (interquartile range), or number (\%).

Table 3. one minute systemic circulation arrest (OSCA) 


\begin{tabular}{|c|c|c|c|}
\hline Variates & $\begin{array}{c}\text { Modified Y-Graft techniques utilizing } \\
\text { Femoral artery bypass (without OSCA, n=23) }\end{array}$ & $\begin{array}{c}\text { Modified Y-Graft techniques utilizing } \\
\text { Femoral artery bypass (with OSCA, n=28) }\end{array}$ & $\begin{array}{c}\mathrm{P} \\
\text { value }\end{array}$ \\
\hline \multicolumn{4}{|l|}{$\begin{array}{l}\text { Preoperative } \\
\text { characteristics }\end{array}$} \\
\hline Age, years & $46.5 \pm 11.8$ & $46.1 \pm 8.3$ & $\begin{array}{c}\mathrm{P} \square \\
0.05\end{array}$ \\
\hline Male sex & $(n=20) 87.0 \%$ & $(n=22) 78.6 \%$ & $\begin{array}{c}\mathrm{P} \square \\
0.05\end{array}$ \\
\hline Weight, Kg & $80.5 \pm 13.4$ & $80.8 \pm 12.6$ & $\begin{array}{c}\mathrm{P} \square \\
0.05\end{array}$ \\
\hline Marfan syndrome & $(n=2) 8.7 \%$ & $(n=2) 7.1 \%$ & $\begin{array}{c}\mathrm{P} \square \\
0.05\end{array}$ \\
\hline $\begin{array}{ll}\text { Aortic } & \text { valve } \\
\text { regurgitation } & \end{array}$ & $(n=10) 43.5 \%$ & $(n=8) 28.6 \%$ & $\begin{array}{c}\mathrm{P} \square \\
0.05\end{array}$ \\
\hline Diabetes mellitus & $(n=1) 4.3 \%$ & $(\mathrm{n}=0) 0 \%$ & $\begin{array}{c}\mathrm{P} \square \\
0.05\end{array}$ \\
\hline $\begin{array}{l}\text { Smoking, past or } \\
\text { current }\end{array}$ & $(n=20) 87.0 \%$ & $(n=21) 75.0 \%$ & $\begin{array}{c}\mathrm{P} \square \\
0.05\end{array}$ \\
\hline Hypertension & $(n=22) 95.7 \%$ & $(n=26) 92.9 \%$ & $\begin{array}{c}\mathrm{P} \square \\
0.05\end{array}$ \\
\hline Renal dysfunction & $(\mathrm{n}=1) 4.3 \%$ & $(n=2) 7.1 \%$ & $\begin{array}{c}\mathrm{P} \square \\
0.05\end{array}$ \\
\hline Pulmonary disease & $(n=1) 4.3 \%$ & $(n=0) 0 \%$ & $\begin{array}{c}\mathrm{P} \square \\
0.05\end{array}$ \\
\hline $\begin{array}{l}\text { Operative variables } \\
\text { Perfusion and } \\
\text { ischemic times, } \\
\text { minutes }\end{array}$ & & & \\
\hline $\begin{array}{l}\text { Cardiopulmonary } \\
\text { bypass }\end{array}$ & 236(200-290) & 204(169-246) & $\begin{array}{c}\mathrm{P} \square \\
0.05\end{array}$ \\
\hline $\begin{array}{l}\text { Systemic circulatory } \\
\text { arrest }\end{array}$ & $20.6 \pm 6.9$ & $1.6 \pm 1.1$ & $\begin{array}{c}\mathrm{P} \square \\
0.05\end{array}$ \\
\hline Aortic clamp & $105 \pm 25.7$ & $92.9 \pm 35.2$ & $\begin{array}{c}\mathrm{P}[ \\
0.05\end{array}$ \\
\hline $\begin{array}{l}\text { Cerebral circulatory } \\
\text { arrest }\end{array}$ & 0 & 0 & NA \\
\hline $\begin{array}{l}\text { Lowest } \\
\text { nasopharyngeal } \\
\text { temperature, }{ }^{\circ} \mathrm{C}\end{array}$ & 28 & 32 & NA \\
\hline $\begin{array}{l}\text { Concomitant aortic } \\
\text { valve replacement }\end{array}$ & $(n=8) 34.8 \%$ & $(n=3) 10.7 \%$ & $\begin{array}{c}\mathrm{P} \square \\
0.05\end{array}$ \\
\hline $\begin{array}{l}\text { Concomitant } \\
\text { coronary artery } \\
\text { bypass }\end{array}$ & $(n=3) 13.0 \%$ & $(n=1) 3.6 \%$ & $\begin{array}{c}\mathrm{P}[ \\
0.05\end{array}$ \\
\hline \multicolumn{4}{|l|}{ Outcomes } \\
\hline Operative mortality & $(n=2) 8.7 \%$ & $(n=2) 7.1 \%$ & $\begin{array}{c}\mathrm{P}[ \\
0.05\end{array}$ \\
\hline $\begin{array}{l}\text { neurologic } \\
\text { dysfunction }\end{array}$ & $(n=3) 13.0 \%$ & $(n=1) 3.6 \%$ & $\begin{array}{c}\mathrm{P} \square \\
0.05\end{array}$ \\
\hline \multirow[t]{2}{*}{ Respiratory support } & ๑2days $(n=15) 65.2 \%$ & $\begin{array}{c}\square 2 \text { days } \\
(\mathrm{n}=10) 35.7 \%\end{array}$ & $\begin{array}{l}\mathrm{P} \square \\
0.05\end{array}$ \\
\hline & प5days $(n=8) 34.8 \%$ & $\begin{array}{c}\text { घ5days } \\
(\mathrm{n}=3) 10.7 \%\end{array}$ & $\begin{array}{c}\mathrm{P}[ \\
0.05\end{array}$ \\
\hline Acute renal failure & $(n=5) 21.7 \%$ & $(n=1) 3.6 \%$ & $\begin{array}{c}\mathrm{P}[ \\
0.05\end{array}$ \\
\hline
\end{tabular}

NA, not available. Data are reported as mean \pm SD, median (interquartile range), or number (\%).

Figures

Figure 1 
Reconstruction of three branches by using Femoral Artery Bypass (FAB) technique. [A] The construction of three bypasses: femoral artery-to-left common carotid artery bypass, femoral artery-to-left subclavian artery bypass and femoral artery-to- innominate artery bypass. [B] A different method of the anastomosis of the three branches: The grafts connected with innominate artery and left common carotid artery was side-to-side anastomosed before the graft connected with innominate artery was anastomosed to the root of the aorta.
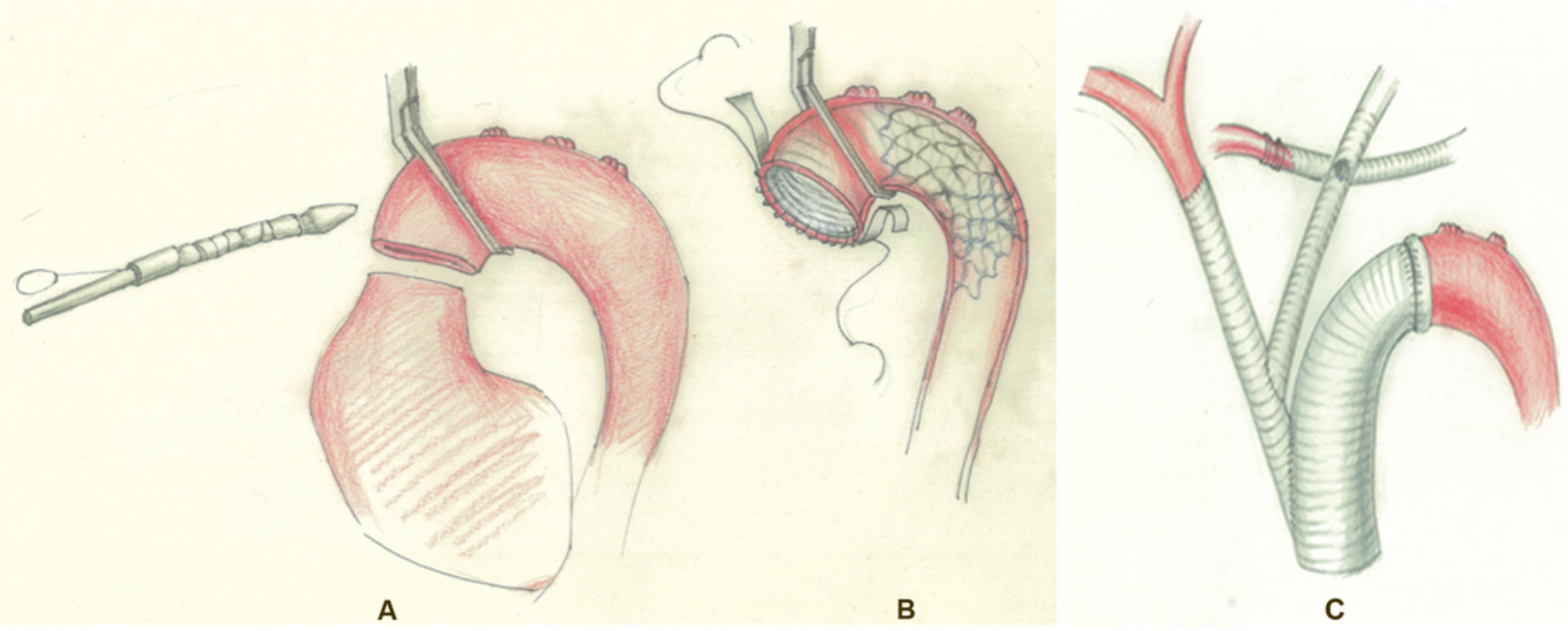

\section{Figure 2}

One minute systemic circulatory arrest during the surgery. The intraoperative stent was placed into the distal aortic arch and then cross-clamped the aortic arch immediately after de-airing, which greatly shortened the duration of the hypothermic circulatory arrest to more or less than one minute. 


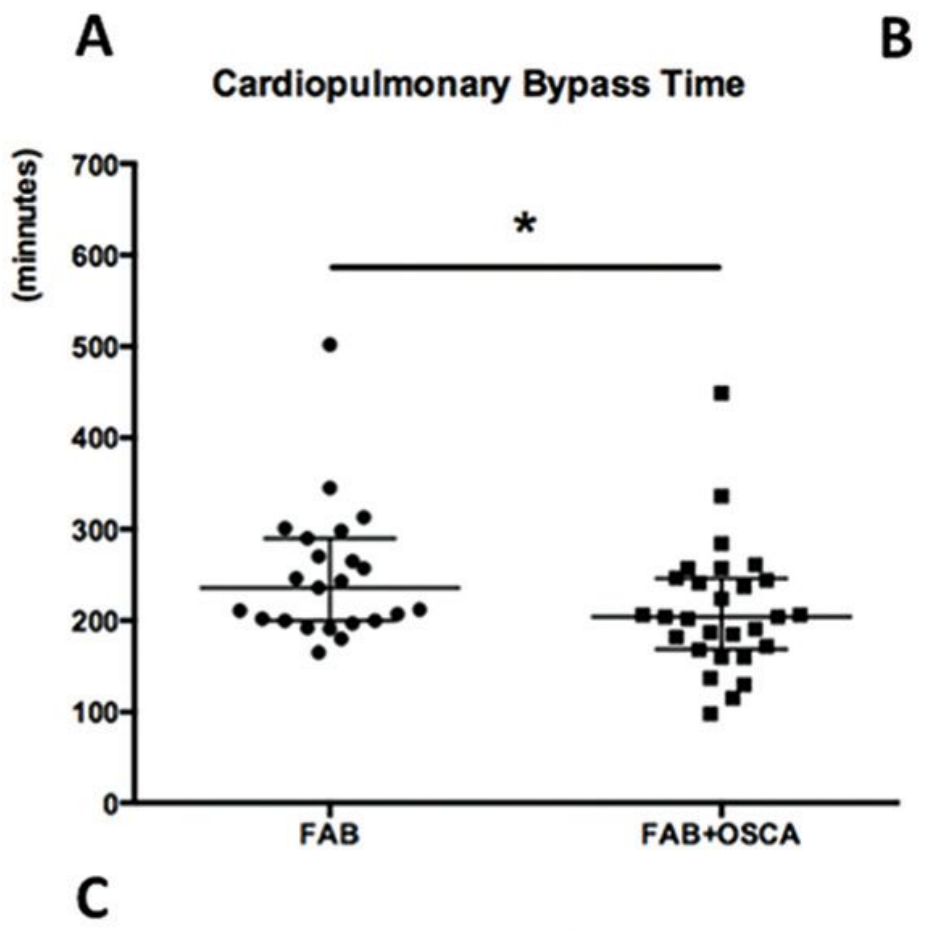

Aortic Clamp Time

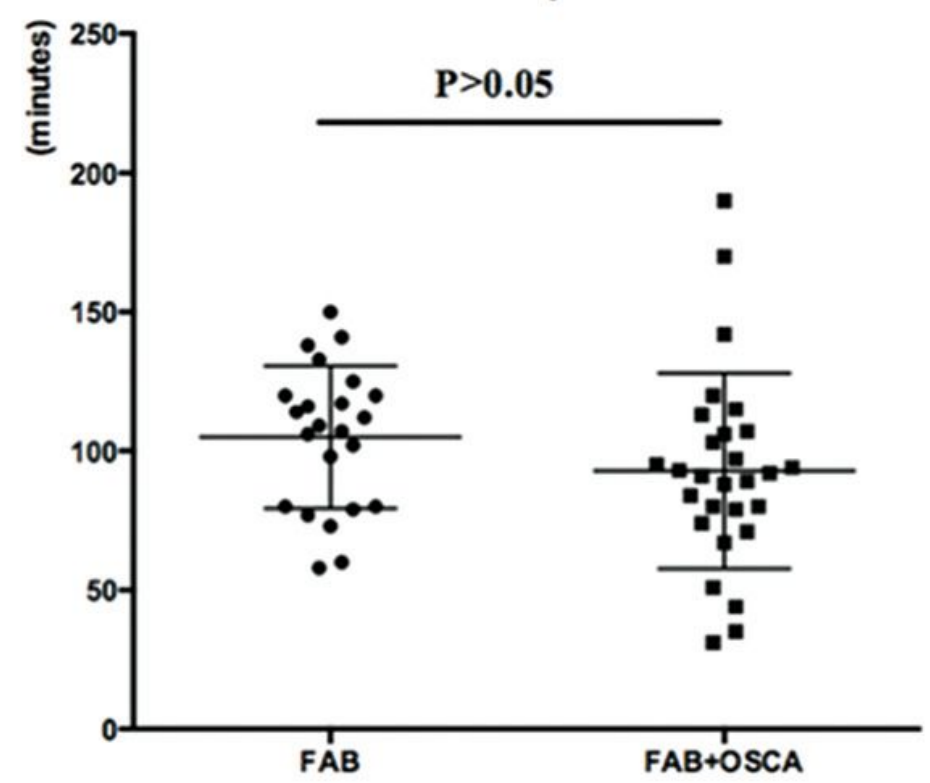

B Systemic Circulatory Arrest Time

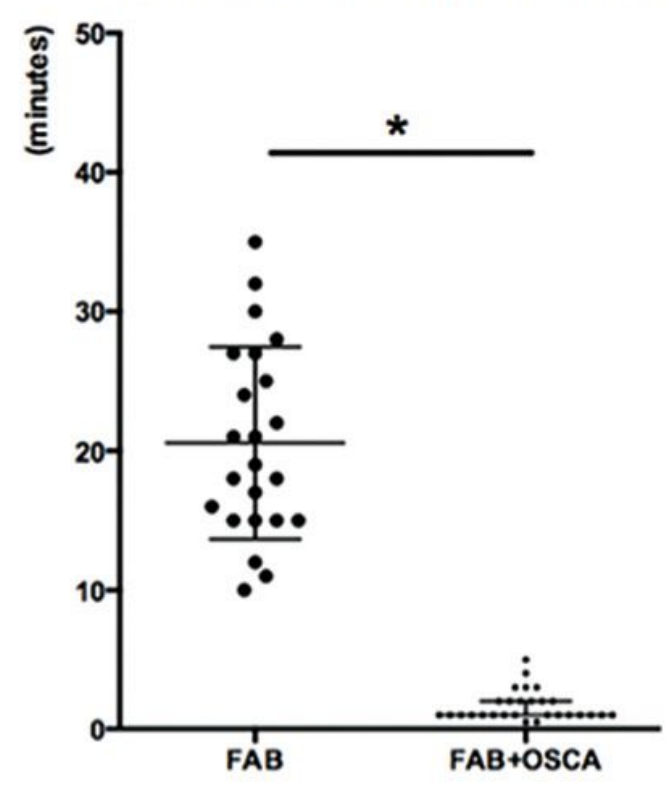

D

\section{Concomitant aortic valve replacement}

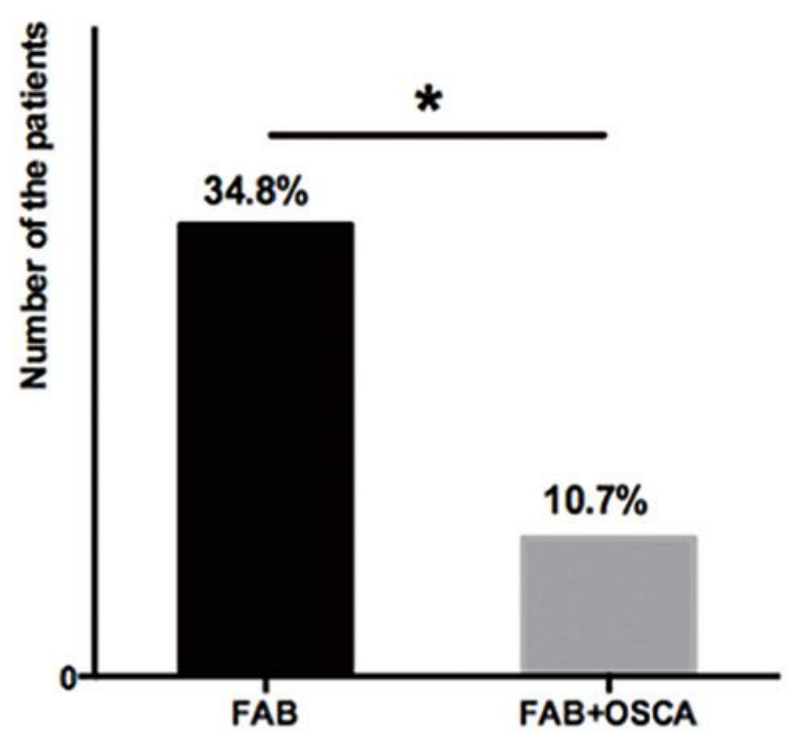

Figure 3

The comparison of the operative variables between the Modified Y-Graft technique using FAB and Modified Y-Graft technique using FAB and OSCA. [A][B] The cardiopulmonary bypass time (236(200-290), 204(169-246), *Pख0.05) and systemic circulatory arrest time $\left(20.6 \pm 6.9,1.6 \pm 1.1,{ }^{*} \mathrm{P} \otimes 0.05\right)$ are significantly shortened after receiving modified $Y$-Graft technique using FAB+OSCA technique. [C] The aortic clamp time has no significantly difference between the two groups $(105 \pm 25.7,92.9 \pm 35.2, P \llbracket 0.05)$. [D] The percentage of the concomitant aortic valve replacement was lower in the patients using FAB+OSCA techniques $(34.8 \%, 10.7 \%, P \bigotimes 0.05)$. The error bars in $A-C$ represent mean $\pm S t d$. deviation. ${ }^{*} P<0.05, t$ test. 
A

Respiratory Support Time

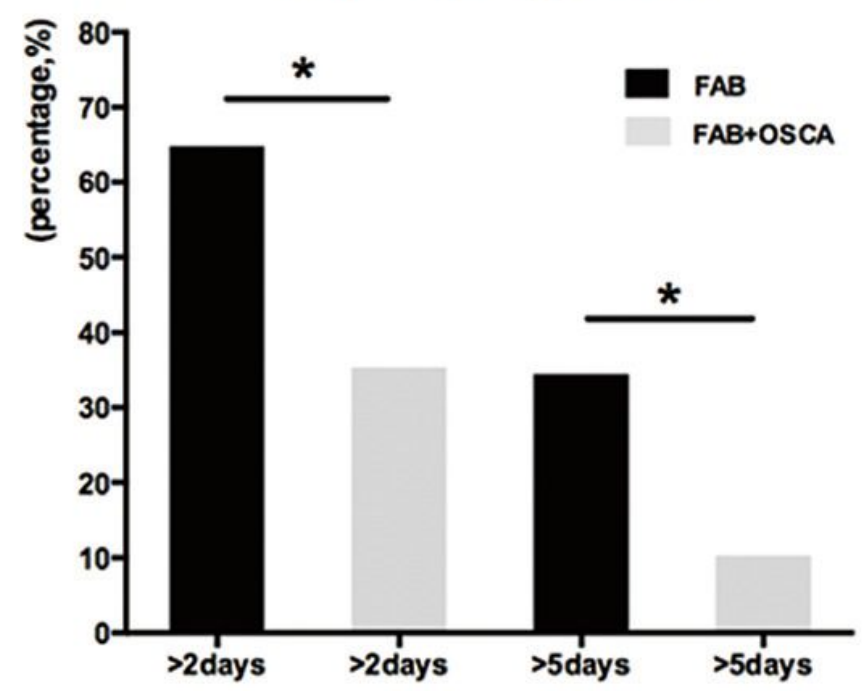

B

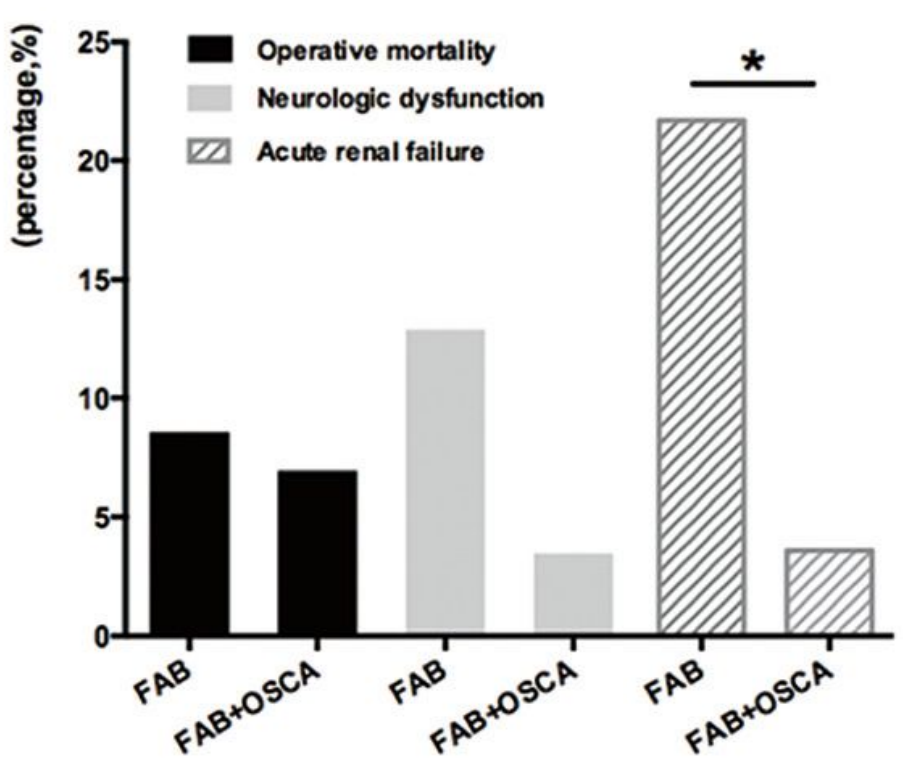

Figure 4

The comparison of the outcomes between the Modified Y-Graft technique using FAB and Modified Y-Graft technique using $\mathrm{FAB}$ and OSCA. The 28 patients who underwent modified Y-Graft technique using FAB+OSCA had an operative mortality of $7.1 \%$ and the morbidity of neurologic dysfunction is $3.6 \%[B]$, and these data is statistically equal to the patients only using FAB. Furthermore, the FAB+OSCA patients had significantly shorter respiratory support duration[A] and lower morbidity of acute renal failure[B]. ${ }^{*} \mathrm{P}<0.05$, chi-square test. 